\title{
Improved Performance of DPFC Using Sliding Mode Controller Method
}

\author{
D. Narasimha Rao ${ }^{1}$, T. Surnedra ${ }^{2}$, S. Tara Kalyani ${ }^{2}$ \\ ${ }^{1}$ Department of Electrical and Electronics, K L University Guntur, India \\ ${ }^{2}$ Department of Electrical and Electronics, JNTU Hyderabad, India
}

\begin{tabular}{l} 
Article Info \\
\hline Article history: \\
Received Jun 9, 2016 \\
Revised Aug 19, 2016 \\
Accepted Sep 2, 2016 \\
\hline
\end{tabular}

\begin{abstract}
Modern power systems demand the need of active power flow with the help of Power Electronics control devices is needed. In the family of Flexible AC Transmission devices (FACTS), Dynamic PFC (DPFC) offers the same controlling function as Unified PFC (UPFC), comprising the control of transmission angle, bus voltage and line impedance. A technical modification of UPFC is DPFC in which fluctuations of voltage at DC link is eliminated that enables the individual operation as series and parallel controllers. The concept of DFACTS is used in design of the series converter. The replacement of the high rating three phase series converter with the multiple low rating single phase converters results in cost reduction and increases reliability greatly. This DC Link is used to transfer the real power between two converters in UPFC such as in DPFC which eliminates the 3rd harmonic frequencies at transmission lines. D-FACTS converters are acting as insulation between high voltage phases acts as $1-\otimes$ floating with respect to ground. These results in lower cost for the DPFC system compared to the UPFC. This paper describes the comparison of PI and Sliding Mode Controllers which conclude that SMC is a better control strategy compared to PI.
\end{abstract}

Copyright (C) 2016 Institute of Advanced Engineering and Science. All rights reserved.

\section{Corresponding Author:}

D. Narasimha Rao,

Departement of Electrical and Electronics Engineering,

K L University,

Guntur, India

Email: narasimharao@kluniversity.in

\section{INTRODUCTION}

The increasing usage of electricity causes more demand in using the renewable energy sources make it compulsory to control a huge power that enables the power system for a quick switch between the renewable energy sources and the stand-by power generation [1]. This demands the availability of stand-by power whenever renewable energy is unable to supply the load. Therefore the need to control the power methods is increased [2]. The parameters used to control voltage value, transmission angle, line impedance are adjusted in order to enhance the power flow. The Power Flow Controlling Device (PFCD) is a device that tries to change system parameters to enhance the power flow performance. The combined FACTS components are the appropriate devices to enhance active power flow [2],[3]. The UPFC is the powerful PFCD, able to adjust line internal angle of the machine, bus voltage, and the parameters of transmission system. The major operation of the UPFC is executed with series converter by injecting the voltage, to control phase angle, magnitude, of the transmission line [3],[4]. DPFC emulates UPFC in independently adjusting the line impedance, control capability, internal angle between the bus voltage and induced EMF [5]. In DPFC there is absence of DC link which makes to interact converters back to back in UPFC [6].

Figure 1 shows the configuration of the DPFC in which each converter within the DPFC is operated independently due to one DC capacitor which provides the required DC voltage. Other than series and 
parallel converters, DPFC needs a filter to bypass high frequency components connected in parallel to the Y$\Delta$ transformer and service transmission line. The need of these extra components is explained later. There are two major advantages of DPFC compared to UPFC:

1. Isolation of low voltage and the series converter's low component rating causes low cost

2. The inability of the series converter in the system causes highly reliable

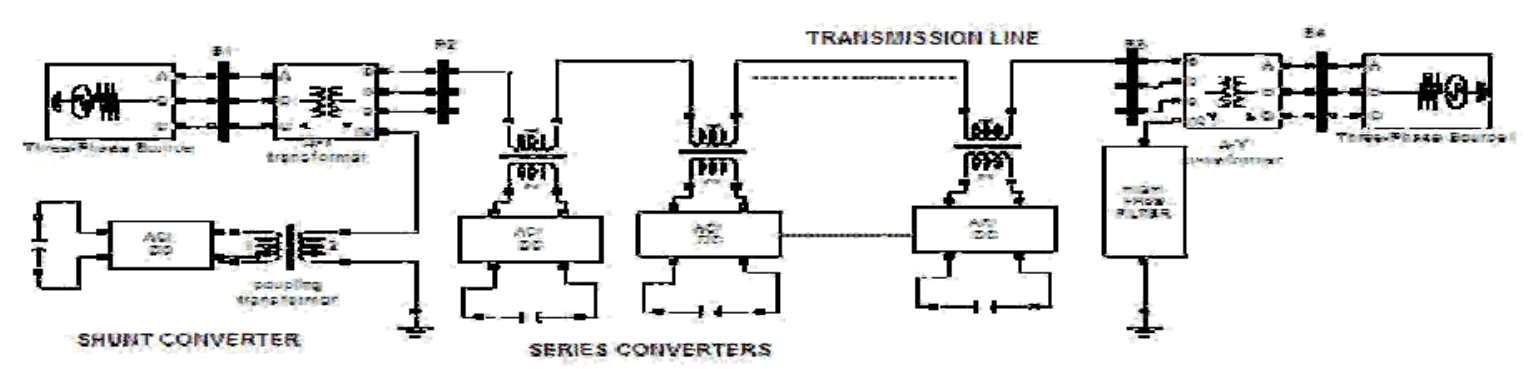

Figure 1. Complete Line Diagram of DPFC System

\section{PRINCIPLE OF DPFC}

In the Unified Controllers, there is common connection between the $\mathrm{AC}$ terminals of series and parallel controllers during exchange of real power. Non sinusoidal components were explained by power theory. In Fourier analysis, the non sinusoidal current and voltage is expressed by including several sinusoidal signals of different frequencies and amplitudes [7]. The real power that results due to non sinusoidal currents and voltages. The real power can be described in equation (1)

$$
P=\sum_{i=1}^{\infty} V_{i} I_{i} \cos \emptyset_{i}
$$

where $I i=$ current, $\mathrm{V} i=$ voltage,$i^{\text {th }}=$ harmonic frequency,

$\emptyset_{i}=$ phase angle between the harmonic currents and voltages.

From the above equation it is observed at different harmonic frequencies of active power are insulated from each other and the real power at other harmonic frequency is not affected by the voltage or current. The real power is independent at different frequencies; this controller without AC supply generating real power at one harmonic frequency to utilise the same power that other component frequency [7],[8]. Following the same approach in DPFC, active power can be absorbed by the parallel converter from source at supply frequency and inserted in to the system at other frequency component. This harmonic component of current flows through the power line. Based on the quantity of real power utilised by the system at the supply frequency, the voltage is generated by the DPFC series converters at the harmonic frequency thus absorbing the power from the line send by the other converter .Here a lossless converter is assumed, so that active power generated at fundamental component frequency and the power absorbed from the harmonic frequency are assumed as equal. The high-pass filter of the DPFC allows the passage of the fundamental components, blocking the harmonic frequency components, by that showing the harmonic components to have a return path. The harmonic current is circulated through high-pass filters, series and parallel converters and the ground. For the exchange of the real power in the DPFC the third harmonic frequency component is identified due to its unique character of the frequency $3^{\text {rd }}$ harmonic components. In a 3-Q system, the fundamental and $3^{\text {rd }}$ multiple component combined inject current into the grid." The zero-sequence harmonics is not allowed by $\mathrm{Y}$ - transformers, which are useful to mitigate reduce voltage level deficiency in power system. Therefore, there is no requirement of excess filter to rest of the network for mitigating the harmonic leakage.

\subsection{Control principle ofDPFC}

Figure 2 shows the three types of controllers that control the multiple converters; they are main control, series control and shunt control. The parameters of series and parallel control are maintained by themselves, they are also called as local controllers. At the system level the central control controls the DPFC functions. The function of these three controllers is given here. 


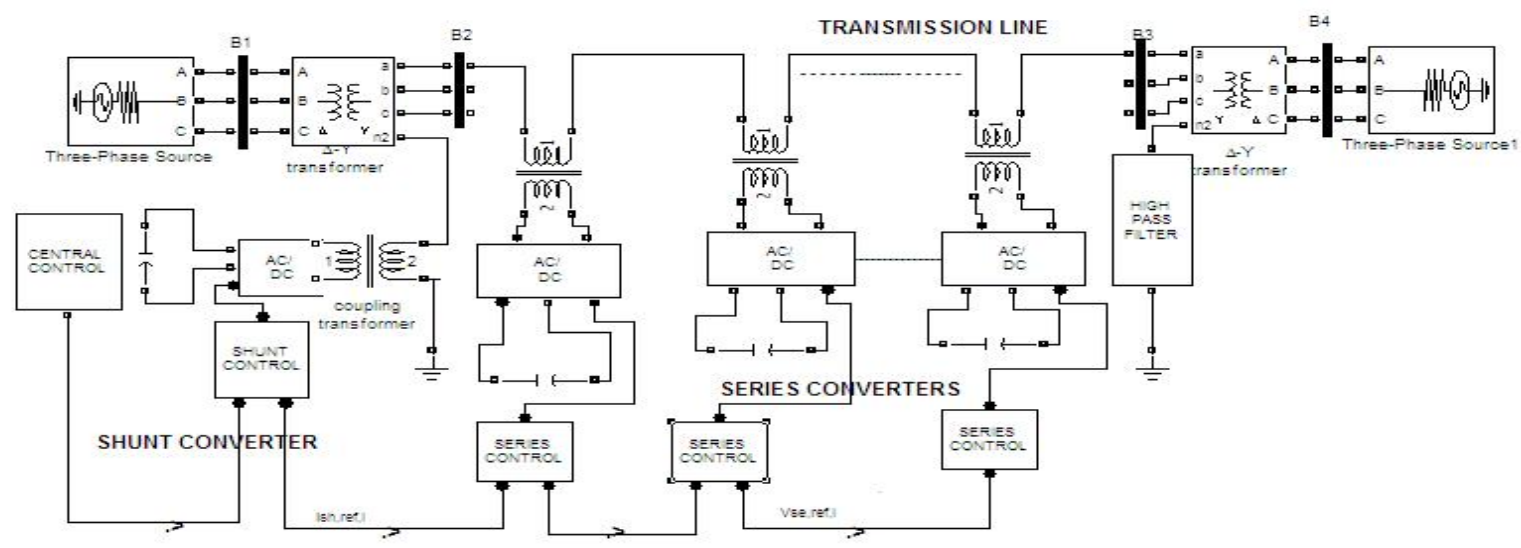

Figure 2. Block Diagram of DPFC with Controller

\subsubsection{Main Control}

The foremost function of the main control commonly known as central controller is to generate reference signals for controlled converters of the DPFC. These are generated at the system frequency. The central control gives reference signal of current and voltages for both the controllers in accordance with the system requirement [5]. At the system level, the central control is dependent on the functional operation of the DPFC; they are damp out power oscillations at low frequency, power-flow control and asymmetrical componentsbalancing.

\subsubsection{Series Control}

Series control is present in all the single phase converter circuits. The controller is to fix the capacitor voltage of converter with help of $3^{\text {rd }}$ harmonic voltage or currents. It injects voltage at supply frequency approved by the main control [6]. In DPFC series converter control, the major control loop is the third harmonic frequency control. For DC voltage control phasor control principle is applied.

\subsubsection{Shunt Control}

It injects a fixed power which combination of fundamental and third harmonic component current into transmission line in order to transmit the real power for series converters is the main objective of shunt control. At the fundamental frequency of the $3^{\text {rd }}$ harmonic current and bus voltage are locked. The motto of parallel converter is to exchange required Q vars to grid and also maintaining fixed DC capacitor voltage.

\section{CONTROLLER DESIGN}

\subsection{Controller design using PI}

The transfer function of the PI controller is described as:

$$
H(s)=K_{P}+K I_{s}
$$

Proportional gain is derived using $\mathrm{KP}=2$..$\omega n$.C which calculates the performance of the DC link voltage control. Similarly, the integral gain is derived using $K I=\mathrm{C} \omega \mathrm{n} 2$ that determines its settling time. The PI controller is to set the DC-link voltage as amplitude of the $\mathrm{d}$ axis current of the APF inverter to control the DC-link voltage for covering the inverter losses based on its reference value [9]. The difference of reference value of the APF current and measured value measured load current

\subsection{Sliding Mode controller (SMC) of DC voltage}

SMC strategy has been commonly applied for power converters problems, due to its operation characteristics such as stability, response fast and robustness during high variation in load [10]. The control action SMC utilizes SM theory as a jump function which is given by the equation (3)

$$
s(y)=k \cdot \operatorname{sign}(\mathrm{y})
$$


The Lyapunov function must be brought to zero; and to achieve this, it is sufficient that its derivative is not positive [10]. To minimize the chattering phenomenon due to the discontinuous nature of the controller, it is necessary to define a different function in neighborhood of the sliding surface with maximum and minimum limit value. If a point of the state trajectory falls within this interval, a smooth function can replace the discontinuous part of the control. Thus, the controller becomes [11].

$$
\begin{aligned}
& u n=\{k c / \varepsilon \text {. (y) if }|s(\mathrm{y})|<\varepsilon \neq 0 \\
& k c .(s(\mathrm{y})) \text { if }|s(\mathrm{y})|>\varepsilon
\end{aligned}
$$

Where, kc represents the optimal gain value. In order to control the DC link voltage Vdc and to remove the chattering by using this SMC, the block diagram of the SMC strategy is given by Figure 3. According to Figure 3, the sliding surface $d s(y) / d y=0$ is used to synthesis a command current $I^{*}[12],[13]$. In this case I* is given by

$$
I^{*}=k c . s(\sigma c)
$$

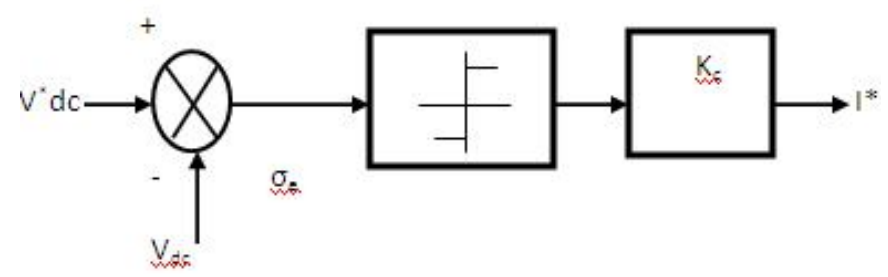

Figure 3. Block diagram of SMC Controller for voltage regulation

\section{SIMULATION RESULTS}

To simulate the SMC or PI controlled DPFC, a model in Matlab/Simulink is developed. Simulation works are carried out to analyze the DPFC performance in a transmission system. A two bus power system is considered for simulation. Active Power flows between the two bus systems are obtained by allowing different phase between the two system. DPFC consists of 6- single phase series converters and shunt controller. The parallel converter is a $1-\otimes$ controller placed between neutral point of $-Y$ transformer and solid ground, and on the other side of it is energised by constant DC source. Here a transmission system with a voltage of $380 \mathrm{~V}$ and $50 \mathrm{~Hz}$ is considered.

Table 1. System Parameters in Simulink

\begin{tabular}{ccc}
\hline Parameter & Abbreviation & Value \\
\hline $\mathrm{Vs}$ & Sending end voltage & $220 \mathrm{~V}$ \\
$\mathrm{Vr}$ & $\begin{array}{c}\text { Receiving end voltage } \\
\text { Inductance component } \\
\text { in line }\end{array}$ & $210 \mathrm{~V}$ \\
$\mathrm{~L}$ & $\begin{array}{c}\text { Angle between two end } \\
\text { bus voltages }\end{array}$ & $1^{\circ}$ \\
\hline
\end{tabular}

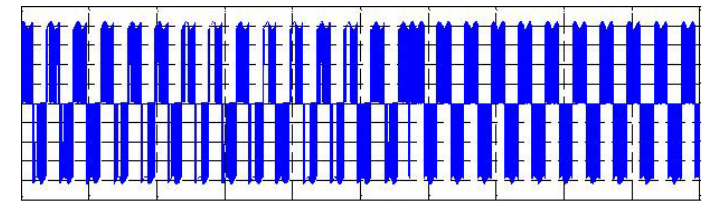

\begin{tabular}{|c|c|c|}
\hline Symbol & Description & Value \\
\hline Vsh,max & $\begin{array}{l}\text { Maximum shunt voltage by } \\
\text { shunt converter }\end{array}$ & $50 \mathrm{~V}$ \\
\hline Ish,max & $\begin{array}{l}\text { Maximum shunt current by } \\
\text { shunt converter }\end{array}$ & $9 \mathrm{~A}$ \\
\hline Ish,ref, & $\begin{array}{l}\text { Shunt converter reference } \\
\text { third harmonic current }\end{array}$ & $3 \mathrm{~A}$ \\
\hline Vsh,dc & dc source supply & $20 \mathrm{~V}$ \\
\hline Vse, $\max 3$ & $\begin{array}{l}\text { SereisconverteMaximum ac } \\
\text { voltage at line side of }\end{array}$ & $7 \mathrm{~V}$ \\
\hline fsw & $\begin{array}{l}\text { Sereis Converter Switching } \\
\text { frequency for shunt and }\end{array}$ & $6 \mathrm{kHz}$ \\
\hline Ise, $\max$ & $\begin{array}{l}\text { Sereis Converter peak ac } \\
\text { current at line terminal of }\end{array}$ & $15 \mathrm{~A}$ \\
\hline
\end{tabular}

Figure 4. Series injected Voltage
Table 2. Measured Values of converter

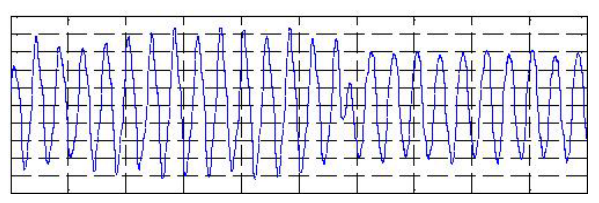

Figure 5. fundamental component of injected voltage 


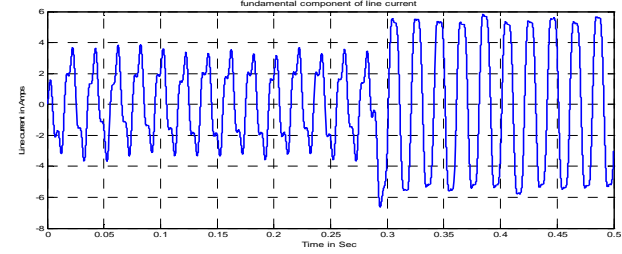

Figure 6 Fundamental Line Current

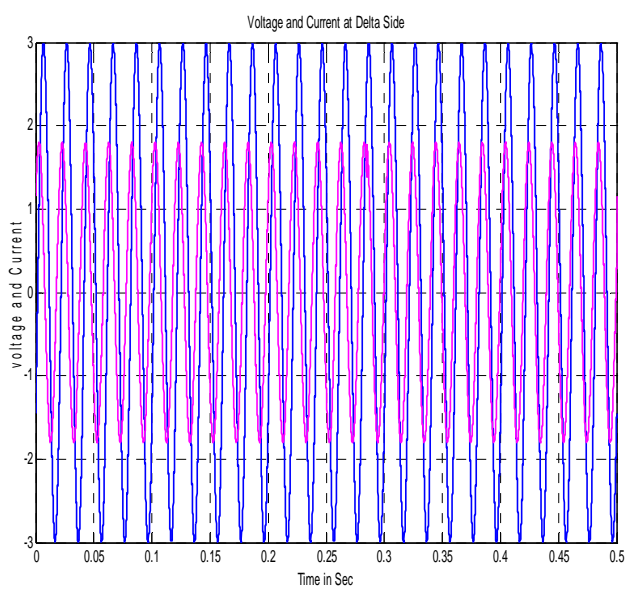

Figure 8. V and I Delta Side

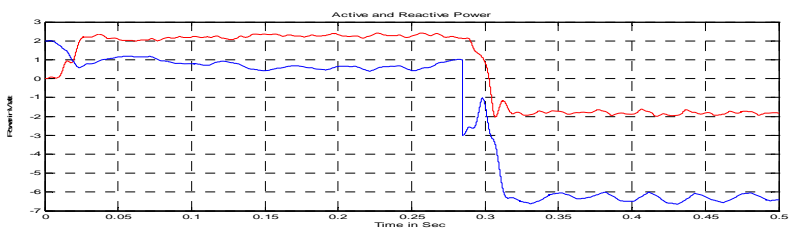

Figure 7. Active and Reactive Power

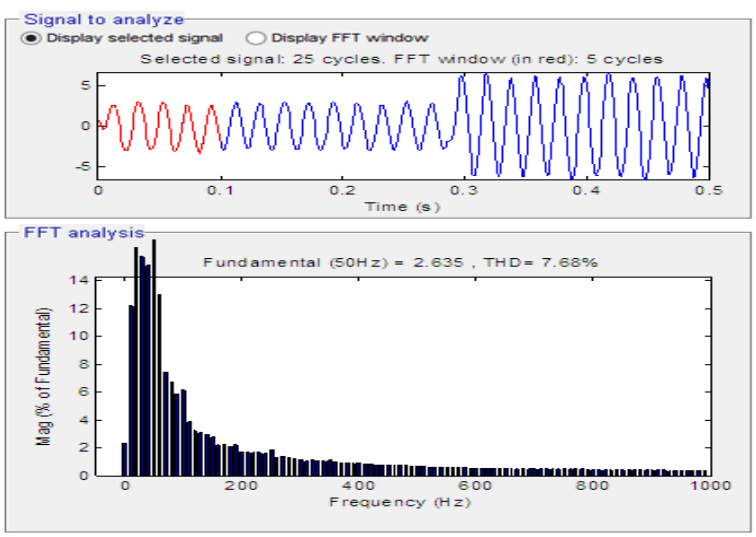

Figure 9. THD Analysis at current at receving end Side
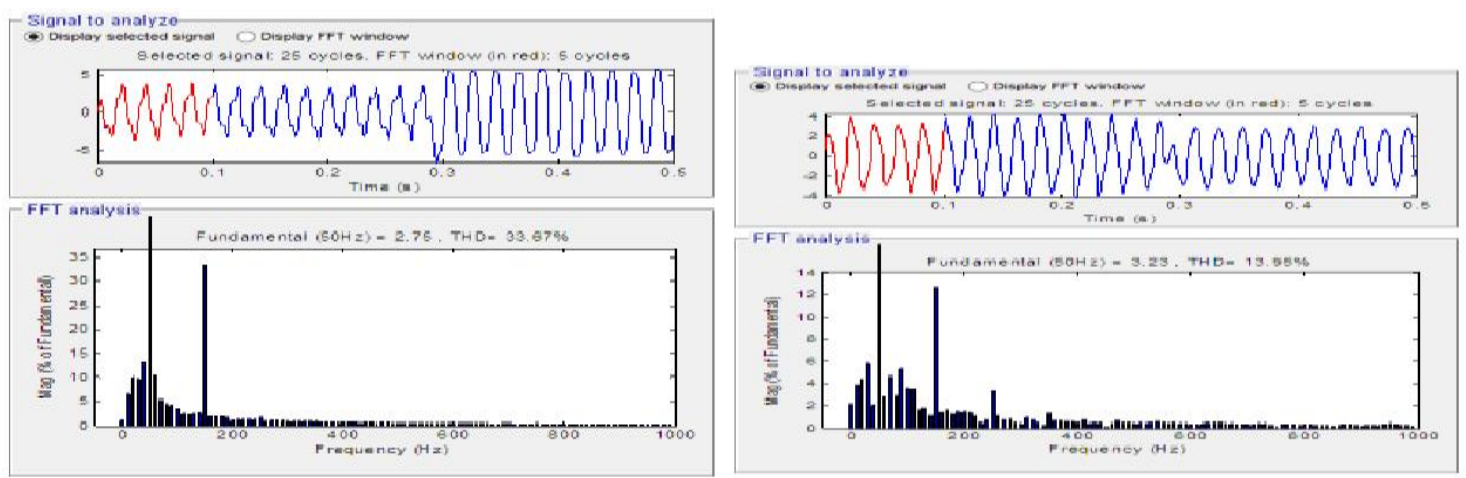

Figure 10. THD Analysis of voltage at receiving end Figure 11. THD analysis of Current at receiving end

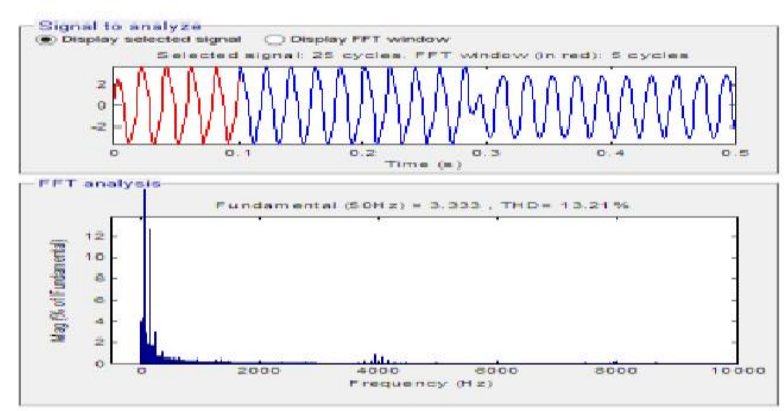

Figure 12. THD analysis-Voltage

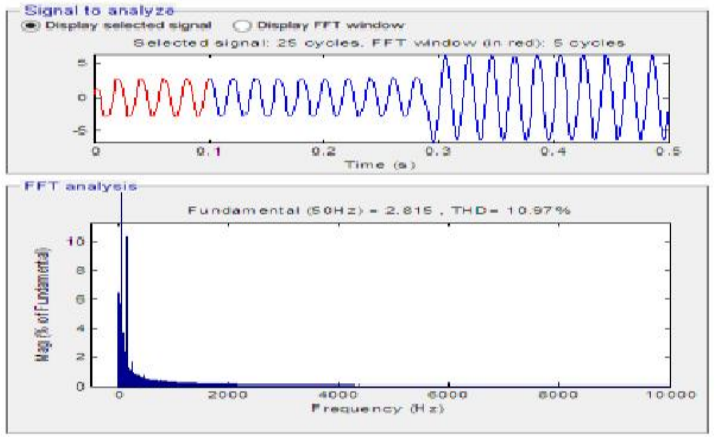

Figure 13. THD analysis- Current 


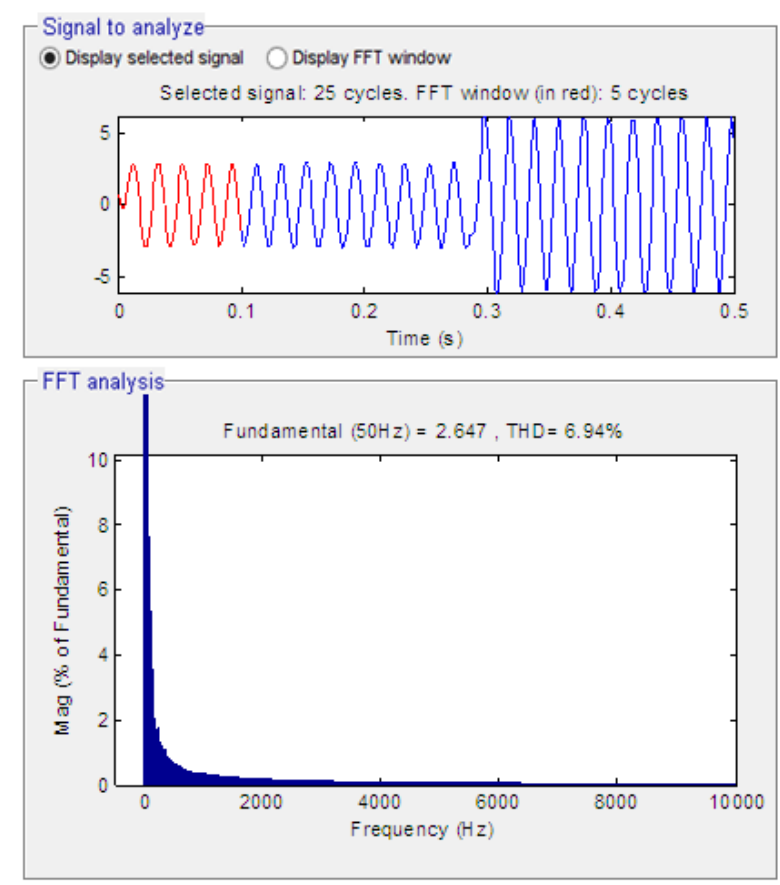

Figure 14. THD analysis- I

Table 3. Contains Performance Differences in Numerical with PI and SMC Method

\begin{tabular}{lcc}
\hline & PI & SMC \\
\hline Series inject voltage (1st and 3rd) component & $78.9 \%$ & $75 \%$ \\
Pundamental injected voltage & $14 \%$ & $13.2 \%$ \\
Line current & $12.96 \%$ & $10.9 \%$ \\
Current receving end & $7.68 \%$ & $6.9 \%$ \\
\hline
\end{tabular}

\section{CONCLUSION}

Two different control strategies for DPFC are presented in this paper. The first is based on proportional-integral controller (PI) and the second uses a sliding mode control (SMC). These controllers are used in order to regulate the voltage of the series controllerto improve dynamical performances. Several conditions have been performed in order to prove the THD of series injected voltage. The simulation is done using MATLAB/SIMULINK. The results obtained by simulation show that the SMC controller offers better performances than the PI. Table is given above.

\section{REFERENCES}

[1] Y. H. Song and A. Johns, "Flexible ac Transmission Systems (FACTS)," IEE Power and Energy Series, vol. 30. London, U.K, Institution of Electrical Engineers, 1999.

[2] N. G. Hingorani and L. Gyugyi, "Understanding FACTS: Concepts and Technology of Flexible AC Transmission Systems," New York, IEEE Press, 2000.

[3] L. Gyugyi, et al., "The unified power flow controller: A new approach to power transmission control," IEEE Trans. Power Del., vol/issue: 10(2), pp. 1085-1097, 1995.

[4] A. A. Edris, "Proposed terms and definitions for flexible ac transmission system (facts)," IEEE Trans. Power Del., vol/issue: 12(4), pp. 1848-1853, 1997.

[5] Y. Zhihui, et al., "Utilizing distributed power flow controller (dpfc) for power oscillation damping," in Proc. IEEE Power Energy Soc. Gen. Meet. (PES), pp. 1-5, 2009.

[6] D. Divan and H. Johal, "Distributed facts-A new concept for realizing grid power flow control," in Proc. IEEE 36th Power Electron. Spec. Conf. (PESC), pp. 8-14, 2005.

[7] M. D. Deepak, et al., "A distributed static series compensator system for realizing active power flow control on existing power lines," IEEE Trans. Power Del., vol/issue: 22(1), pp. 642-649, 2007.

[8] K. K. Sen, "SSSC-static synchronous series compensator: Theory, modeling, and application," IEEE Trans. Power Del., vol/issue: 13(1), pp. 241-246, 1998. 
[9] Y. Sozer and D. A. Torrey, "Modeling and control of utility interactive inverters," IEEE Trans. Power Electron., vol/issue: 24(11), pp. 2475-2483, 2009.

[10] L. Huber, et al., "Review and stability analysis of pll-based interleaving control of $\mathrm{dcm} / \mathrm{ccm}$ boundary boost pfc converters," IEEE Trans. Power Electron., vol/issue: 24(8), pp. 1992-1999, 2009.

[11] M. Mohaddes, et al., "Steady state frequency response of statcom," IEEE Trans. Power Del., vol/issue: 16(1), pp. $18-23,2001$.

[12] A. Ajami and A. M. Shotorbani, "Design and Comparison of a Novel Controller Based on Control Lyapunov Function and a New Sliding Mode Controller for Robust Power Flow Control Using UPFC," Gasi University Journal of Science, vol/issue: 27(1), pp. 679-692, 2014.

[13] B. Mohamed and M. Mohamed, "Power System Stability Enhancement by STATCOM using Sliding Mode Control and Lyapunov's Method Control," The 2nd International Conference on Power Electronics and their Applications (ICPEA 2015), At Djelfa, Algeria, 2015. 